\title{
Behavioral Economics in Military Personnel Research and Policy
}

\author{
Benjamin Sylvester, Damian O'Keefe, Steve Gooch, and \\ Eugenia Kalantzis
}

\section{Contents}

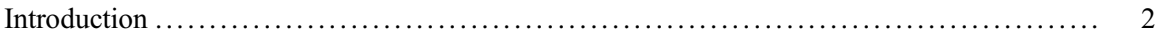

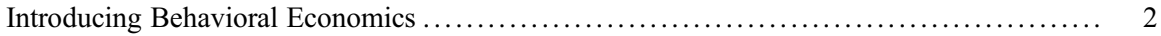

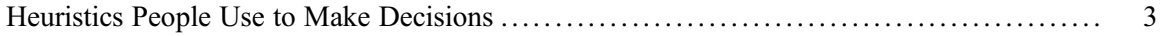

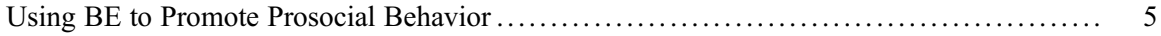

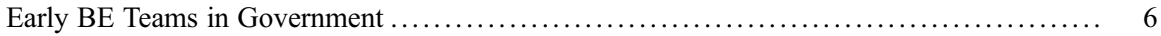

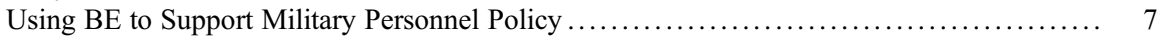

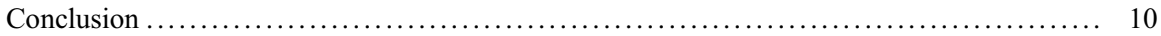

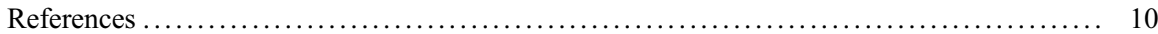

\section{Abstract}

Behavioral economics is a burgeoning field of research that is being used to increase the effectiveness of military policies, programs, and operations. This chapter provides an overview of the origins of behavioral economics, key concepts, how behavioral economics research translates into applied behavioral change, and the rise of behavioral economics teams in government around the world. The chapter outlines how behavioral economics is being used within the military, with specific examples from Canadian Armed Forces (CAF) personnel research to illustrate how this field is being applied to military behavioral sciences.

\section{Keywords}

Nudge $\cdot$ Choice architecture $\cdot$ Behavioural insights $\cdot$ Government

B. Sylvester · S. Gooch · E. Kalantzis

Ottawa, ON, Canada

e-mail: ben.sylvester@forces.gc.ca; steve.gooch@forces.gc.ca; eugenia.kalantzis@forces.gc.ca

D. O'Keefe (ه)

Director General Military Personnel Research and Analysis, Department of National Defence, Ottawa, ON, Canada

e-mail: damian.o'keefe@forces.gc.ca 


\section{Introduction}

Governments around the world have sought to save money, improve services, and demonstrate the effectiveness of their services using Big Data. Approaches that bridge the gap between scientific discovery and implementation have received much attention and funding, especially behavioral economics (BE), which attempts to increase the effectiveness of policies, programs, and operations by influencing the decisions and behaviors of individuals. In recent years, initiatives based on BE have been appearing in governments around the world. From a military perspective, BE interventions have been primarily useful in enhancing military attraction and recruitment programs (see Behavioural Insights Team (BIT) 2015; Gooch and Kemp 2018; O'Keefe et al. 2018a, 2018b).

This chapter provides an overview of the seminal work and key concepts in BE, how $\mathrm{BE}$ translates into behavioral change, and the development of BE teams in government around the world. The chapter concludes with an overview of the work conducted in support of Canadian Armed Forces (CAF) personnel policy to illustrate how this field is being applied to military behavioral sciences.

\section{Introducing Behavioral Economics}

The field of BE grew out of the finding that people make decisions in two ways, one quick and intuitive, the other slow and effortful. Kahneman and Tversky (1972, 1973) and Stanovich and West $(1998,2000)$ were among the first researchers to investigate what came to be known as the dual-processing model of thinking. One way of reasoning (named System 1) involves intuitive, fast decision making, which, on the surface, appears devoid of reflection. Kahneman and Tversky (1973) found, however, that System 1 thinking generally relies on heuristics and prior learning (Stanovich et al. 2011). The other way of reasoning (called System 2) is what we conventionally associate with rational thinking; the more laborious, deliberate, and reflective thought process, which involves hypothesizing and requires working memory and general intelligence. This chapter deals mostly with System 1 thinking.

In recent years, the dual-processing model has reached mainstream media through books such as Daniel Kahneman's (Winner of the 2002 Nobel Memorial Prize in Economic Sciences) Thinking, Fast and Slow (2011), Richard Thaler (Winner of the 2017 Nobel Memorial Prize in Economic Sciences) and Cass Sunstein's Nudge: Improving Decision about Health, Wealth and Happiness, (2008), and Dan Ariely's Predictably Irrational: The Hidden Forces That Shape Our Decisions (Thaler \& Sunstein, 2008). These works were seminal in the field of BE and are must-reads for those new to the field.

Within the field of BE, researchers recognize that people do not always behave as predicted by classic economics, where individuals presented with a choice consider all available facts and select the option that maximizes their best interests (Kosters and Van der Heijden 2015). In contrast, BE recognizes bounded rationality, which means people do not have the cognitive capacity to process all available information 
needed to make an optimal decision (Kosters and Van der Heijden 2015; Mullainathan and Thaler 2015). Even when decisions are less complex, the concept of bounded willpower (Kosters and Van der Heijden 2015; Mullainathan and Thaler 2015) recognizes that people tend to resist doing things they know are in their best interest, such as exercising more frequently or taking medications.

The fundamental insights of $\mathrm{BE}$ are derived from a series of experiments by Kahneman and Tversky (1973) showing that people did not make rational choices in various scenarios. More important for the development of $\mathrm{BE}$ were two further findings. First, these experiments revealed that - as the title of Ariely's book suggests - people's choices were predictably irrational, meaning their choices were found to rely on the heuristics associated with System 1 thinking. Second, and equally significant, the decisions people made were influenced by the way the choices were presented, which implied that modifying (what came to be called) the choice architecture could improve people's decision making (Kosters and Van der Heijden 2015). The next section of this chapter looks at the heuristics people use to make decisions, while the following section looks at how the choice architecture can be modified to help people make better choices.

\section{Heuristics People Use to Make Decisions}

People often use mental shortcuts, known as heuristics, to quickly evaluate problems and make snap decisions. These shortcuts usually stem from individual experience, emotion, and personal subjectivity. Heuristics are especially relied upon when making decisions in stressful and ambiguous situations, which are often faced by military personnel. However, heuristics can be detrimental to deliberate, methodical problem reflection and rational decision making. Being aware of common heuristics is the first step in countering their effects and making rational decisions (Businessballs 2014). Following are common heuristics.

Anchoring and adjusting occur when salient but irrelevant facts and estimates influence (or "prime") our decision making (Tversky and Kahneman 1974). One can influence a person's estimate of the population of a city, for example, by providing them with the populations of nearby cities, which are often irrelevant facts.

The availability heuristic occurs when we mistake the frequency at which we see, hear, and read about events with their actual frequency (or popularity) and our likelihood of experiencing such events (Tversky and Kahneman 1973). Mass media strongly influences the availability heuristic. Suicides are far more frequent than homicides, for example, but homicides receive more frequent coverage in the media. Not surprisingly, therefore, survey data show that many people believe homicides are much more frequent than suicides.

Representativeness refers to a shortcut where we default to stereotypes and assumptions when dealing with unknowns which often lead us to make decisions about a situation based on how similar it is to a prototype we hold in our mind. This heuristic is heavily influenced by misinformation and individual experiences (Tversky and Kahneman 1974). In male-dominated professions such as the military, 
the chances of a male being promoted over a female are higher because males fit the military leader prototype better than females.

Loss aversion is our general reluctance to concede or make changes because we value possessing things (more than the things themselves) and fear losing possessions (i.e., the pain of losing something is greater than the pleasure from gaining it; Kahneman and Tversky 1979). For example, people buy insurance because they have a need for security and have a desire to avoid losses and risk. Military personnel who have stronger loss aversion may be more likely to purchase additional insurance for their personal belongings while deployed.

Status quo bias refers to our propensity to "go with the flow" and our reluctance to change our current situation due to fear of the unknown or aversion to complexity - we prefer the more familiar choice over the less familiar (Samuelson and Zeckhauser 1988). For example, people in the military may settle into a role/location and be reluctant to get posted even though there are greater opportunities in a new role/location. To counter status quo bias, many countries have changed the default on organ donation forms from opt-in to opt-out, which has substantially increased the donor population.

Framing refers to the finding that the way information is presented influences how we interpret that information. That is, the description of the choice or situation matters (Tversky and Kahneman 1981). Closely related to framing is priming, which means we are predisposed to certain feelings under certain conditions and that exposure to certain stimuli influences how we respond to subsequent stimuli (Kahneman 2011). A UK study on minority police officer recruitment testing used a priming message to encourage applicants to consider their presence in the police force as a valued social identity vis-a-vis underrepresented communities (i.e., "... . what is it about being a police constable that means the most to you and your community?"). The message closed the gap in selection test scores between non-white and white applicants, suggesting that messaging to reduce stereotype threat (i.e., people aware of a negative stereotype about their group often worry about their performance) can reduce test anxiety for minority applicants (Linos et al. 2017). Similar messaging could be used to encourage women and visible minorities to consider a career in the military since research shows that they perceive themselves to be less fit for service and less confident in meeting entry standards (Manigart et al. 2018).

The spotlight effect arises from the belief that our actions are more visible to others than is really the case. This heuristic is mostly driven by fear of embarrassment, making mistakes, and criticism, which can lead to poor decisions. Of course, most individual actions are almost invisible to other people (Gilovich et al. 2000). Spotlight effect is especially prevalent among people who are high in selfmonitoring (i.e., being highly conscious of one's actions or appearance). Brand marketing, for example, exploits the spotlight effect by persuading us that a product is popular among our peers (e.g., wearing a brand-name shirt because people notice). Another example of the spotlight effect is when military recruits believe others (outside of the military) are evaluating their performance on cognitive ability tests, despite knowing these tests are confidential. 
The following the herd heuristic refers to our desire to conform to a perceived norm to be part of a group and our need for affirmation and to avoid risk. This shortcut underlies peer pressure, the "mob effect," and the spread of myths, fashions, and fads (Scharfstein and Stein 1990). The following the herd heuristic could explain why normally law-biding people might be influenced by mob mentality that transfers a peaceful rally into violence and looting.

Optimism is bias toward underestimating the costs, timeframes, and complexities of a challenge, as well as overestimating its benefits. This shortcut can lead to denial, waste, insufficient planning, as well as unmet deadlines (Weinstein and Klein 1996). Many large projects undertaken in the public and private sectors are neither on-time nor on-budget, largely due to the optimism heuristic. The optimism heuristic can also explain why we engage in unhealthy but immediate, self-gratifying behaviors such as smoking, drinking, and overeating; we optimistically assume that the negative consequences of unhealthy behavior (i.e., poor health) are unlikely to materialize for us.

\section{Using BE to Promote Prosocial Behavior}

From a policy perspective, BE proponents argue that leaders and organizations should move away from traditional control mechanisms, such as banning certain options, punishment, regulations, and financial incentives. Instead, policymakers should use BE interventions to change an individual's choice architecture. The examples provided for each $\mathrm{BE}$ technique below have not been tested but are based on existing evidence. These examples are provided to give you a sense of how BE can be applied to military behavioral research:

- Provide information. Letting women know that they have a high chance of success in basic training (e.g., 9 out of 10 women pass basic training) could aid recruitment efforts by encouraging women to enlist (Khan and Hardy 2018).

- Attract attention. Use attractive signs and display cases for healthier eating options in military cafeterias, for example, to encourage members to choose healthy foods (Winkler et al. 2016).

- Persuasion. Display images of strength and success of those who have been injured in combat to persuade others to use services available to ill and injured military members (c.f. Park and Crocker 2013).

- Reciprocity. Including some gear (e.g., t-shirt) in promotional material for prospective recruits, for example, could prompt individuals to reciprocate by registering for future events/more information (cf. Cialdini and Goldstein 2004).

- Social norms. Because people look to others to inform their own decision making, perhaps indicating, on a military recruiting website, the number of people who have started an online application may influence others to consider the military as a career (cf. Cialdini et al. 1990). 
- Personal touch. Including a note of encouragement or congratulations in an email or letter, for example, can encourage military applicants to continue with the recruitment process (Dolan et al. 2012).

- Default options. Altering the default option on registering for veteran services forms from an opt-in to an opt-out, for example, could increase uptake (Halpern 2016).

These and other techniques are used to develop nudges, which are unintrusive, low-cost, interventions that increase the likelihood of people selecting a particular option (or engaging in certain behavior) without restricting freedom of choice (Halpern 2016). Nudges encourage prosocial behavior, are open and transparent, and allow freedom of choice. People generally support nudges when they think that they have a legitimate purpose and when the objective is consistent with social interests and values (Reisch and Sunstein 2016). Nudges employ a variety of techniques to leverage heuristics and biases by altering the choice architecture presented to the individual - that changes how they view the relative attractiveness of the choices available to them (Kosters and Van der Heijden 2015; STSC 2011). As discussed later in the chapter, nudges can be used in military organizations in areas such as encouraging applicants to continue the application process; reducing test anxiety; and promoting healthy lifestyles.

\section{Early BE Teams in Government}

Governments began creating BE teams in 2010 when UK Prime Minister David Cameron established the Behavioural Insights Team, which later became known as the Nudge Unit (Halpern 2016). Headed by Dr. David Halpern (a psychologist), this team implemented relatively simple, low-cost interventions that influenced prosocial behaviors. Beginning with text messages, rewording letters, and sending personalized emails (Rutter 2015), their objective was to "improve the efficiency and effectiveness of government policies, without requiring anyone to do anything" (Halpern 2016: foreword by Richard Thaler). In February 2014, the team broke out of government and became a private entity (Rutter 2015). Its reach has disseminated across Europe and internationally, with projects undertaken in France, Germany, the US, Canada, and on behalf of the European Commission (Kosters and Van der Heijden 2015) and the World Bank (Halpern 2016).

In 2014, the US White House Office of Science and Technology Policy stood up the Social and Behavioural Sciences Team (SBST) whose goal was to "translate findings and methods from the social and behavioural sciences into improvements in federal policies and programs" (SBST 2015). Since the change of administration on January 20, 2021, a new Memorandum on Restoring Trust in Government Through Scientific Integrity and Evidence-Based Policymaking was issued. It restores the Executive Order under President Barack Obama that stipulates policies and programs be informed by behavioral science. In Canada, Canada Revenue Agency (CRA) has explored behavioral insights techniques as well. The CRA included 
positive and negative prompts in letters that were sent to those who owed taxes and obtained a modest increase in the number of people who visited a web page, but did not change the amount of income they reported, or the number of people who requested a correction to their tax return (Results of the Canada Revenue Agency's 2015-2018 Underground Economy Strategy, 2018). Further, the Privy Council Office Innovation Hub has been supporting federal departments and agencies in applying novel policy and program tools since 2015 (Central Innovation Hub Privy Council Office, 2016).

An example of the Privy Council Office Innovation Hub's work is its social media study aimed at encouraging recruitment of women into the Canadian Armed Forces (CAF), undertaken in concert with the Department of National Defence. The trial involved social media (Facebook and Instagram) messaging and imagery along several themes, including humanitarianism, the educational benefits of the CAF, and the general challenge of being a CAF member. The most salient message was one challenging assumption about women's success in military (e.g., the campaign used the figure "9 out of 10 women succeed at basic training - be one of them!"). The message received one of the highest responses, amounting to over $3 \%$ of visitors clicking on the ad. This result significantly outperformed the Canadian government average for social media, which is typically at about $1 \%$ of visitors (Khan and Hardy 2018). These results help inform military recruiters with regard to recruitment campaigns, including campaigns aimed at underrepresented groups such as women.

\section{Using BE to Support Military Personnel Policy}

Despite the transparency of BE in government, there is a dearth of evidence that BE is used in militaries around the world. Principles of BE may be used internationally by military organizations, but $\mathrm{BE}$ research in military contexts is not always documented in academic journals or easily located. Two examples of using BE in military contexts include the UK and the US. In the UK, BIT (2015) reported a study in which they increased the proportion of candidates in the recruitment process who submitted their application form. Specifically, large numbers of people would dropout between the initial expression of interest in joining the Army and those who eventually signed up. By upgrading the existing customer relationship management system through emails and marketing communications materials, BIT was able to almost double the proportion of candidates who completed the process. In the US, use of BE in the military is primarily evidenced through media outlets. For example, America Abroad (2017) documented how the US military uses BE to fight ISIS. As one example of how BE has been used, leaflets that contained cartoon graphics were used to communicate safe routes for civilians to cross boundary lines and what they should do to cross lines safely (America Abroad 2017). Despite some evidence from $\mathrm{BE}$ team reports and media sources, credible documentation of $\mathrm{BE}$ research is needed to advance the global scope of BE in the military.

Canadian Armed Forces Examples. At present, apart from some work being conducted for the UK Army by BIT, there is little formal use of BE within military 
organizations. Recognizing this need, in 2017, the CAF established a BE team, Personnel Research in Action (PRiA), within the Chief of Military Personnel's social science research laboratory (Director General Military Personnel Research and Analysis: DGMPRA). The PRiA team develops and maintains expertise in BE program assessment, science-policy integration, and iterative design methods. In this section, we describe some work conducted by PRiA to provide an example of how BE can be used within military organizations to complement existing personnel policies.

In support of the Canadian Forces Recruiting Group, PRiA's first tasking was to develop nudges to encourage prospects to remain engaged in the recruitment process. To this end, a series of nudges consisting of personalized email messages that invited CAF prospects who had abandoned their application to continue with the recruitment process were developed (O'Keefe et al. 2018a, 2018b; Gooch and Kemp 2018). The inspiration for these nudges came from interventions designed by BIT (2015) to enhance the application process of the British Army Reserve. In addition, interventions were informed by the concept of social influence, which holds that people look to the behavior of others for guidance (Cialdini 2001), the MINDSPACE framework (Dolan et al. 2012), which suggests that the perceived authority of the messenger determines the strength of the message, and research by Durantini et al. (2006), which showed that people are more likely to act on information when the messenger is similar to themselves.

Several messages were trialed to see how they would influence CAF prospects to continue with the application process. For example, in one study (O'Keefe et al. 2018 b), based on role-modeling research, three personalized messages were trialed (one from a male sender, one from a female sender, and one with no gender specified) to test whether the sex of the sender affected the application decisions of male and female prospects. In other research, a meta-analysis of mentoring studies reported a positive link between mentoring programs (i.e., role models) and careerrelated outcomes (e.g., career success, job satisfaction; Allen et al. 2004), but research on the role of same-gender mentors is mixed (see Lockwood 2006). Recent role-modeling research with college students (a similar age cohort as CAF prospects), however, has found that strong female role models have a stronger impact on female protégés than male role models but that the gender of the role model had no effect on male protégés (Lockwood 2006). Based on this research, it was expected that female prospects would relate more to the message from a female sender.

Using a randomized controlled trial, 3336 CAF prospects (2109 men and 1227 women) who had applied for the CAF, but their file was flagged for inactivity (i.e., they had not contacted the CAF recruitment center in the previous 90 days), were sent one of three messages (i.e., message from a male sender, a female sender, or a generic message). This method allowed the researchers to determine whether and what kind of message encourages prospects to continue with the application process. The emails resulted in 1786 visits to the CAF website and 152 prospects re-opening their application. In all messaging trials, about $5 \%$ of prospects re-opened their applications (O'Keefe et al. 2018a, 2018b), supporting the use of email messages to encourage prospects to continue with the application process. 
Another Canadian study is examining whether brief interventions can improve the accuracy of selection test scores by reducing takers' test anxiety. Test anxiety is prevalent (Chang and Beilock 2016) and the level of anxiety recruits experience writing selection tests could adversely affect their performance on the Canadian Forces Aptitude Test (CFAT), which is an assessment of cognitive ability that candidates complete during the recruitment process. The CFAT likely evokes anxiety due to the significant career implications of the score. Thus, the CAF is examining whether two interventions (singly or in combination) can increase scores on the CFAT by mitigating mathematics anxiety. Mathematics anxiety was targeted because it is widely known to influence test-takers' scores (Chang and Beilock 2016).

Other Canadian military BE interventions have focused on improving health and fitness among CAF members. One project involves using nudges to reduce alcohol and tobacco use in the CAF; this project began with a realist review (Xiao and Watson 2019) of the complex social nudge interventions targeting alcohol and tobacco consumption (Sylvester \& Gooch, 2021). Effective nudges used defaults to automatically engage people with the nudge (e.g., the size of glass that alcohol was served; reduced hours for alcohol purchases; Kersbergen et al. 2018). Ineffective nudges were those that aimed to indirectly change behavior (e.g., through an advertisement display or as a piece of information within a larger package) and required participants to pay attention to an external piece of information in order to be nudged (e.g., Brendryen et al. 2017).

Another health-related study looked at increasing completion rates of the CAF's annual fitness test (FORCE Test). CAF members are required to be physically fit, and the FORCE Test is an annual evaluation of health and operation-related fitness that informs senior leaders in the $\mathrm{CAF}$ about how many members are ready to serve. $\mathrm{BE}$ offers effective strategies for increasing attendance rates (Hasvold and Wootton 2011). Human error has been found to decrease attendance rates (e.g., healthcare appointments; Hasvold and Wootton 2011), and simple nudges, such as reminder emails, have been found to increase attendance (Boksmati et al. 2016). As such, email messages will be sent to commanding officers (COs) regarding completion of the FORCE Test among personnel in their unit.

Other $\mathrm{BE}$ interventions within the $\mathrm{CAF}$ involve supporting efforts to increase survey response rates. Survey research plays an important role in the organization by providing CAF members the opportunity to share their experiences and providing CAF leadership with data to make evidence-based decisions. Email reminder messages using BE techniques such as setting a deadline and endorsement from senior leadership appear to be effective in encouraging survey engagement and completion among CAF personnel (Sylvester, Howell et al. 2021; Sylvester, Gooch et al. 2021). 


\section{Conclusion}

Governments are increasingly using BE to influence prosocial behavior and to increase the effectiveness of policies, programs, and operations. Within armed forces organizations, BE researchers can help militaries improve policy outcomes and increase organizational and operational effectiveness and efficiency. This chapter provided an overview of the seminal work in $\mathrm{BE}$, a brief description of the early $\mathrm{BE}$ teams in government, and some of the work being conducted by the CAF's BE team, Personnel Research in Action. As shown, within a military organization, insights from BE can be used to encourage (nudge) prosocial behavior (e.g., survey completion, reducing test anxiety, encouraging application completion). BE interventions are not meant to replace existing policy development activities (that primarily appeal to System 2 thinking) but to complement them. In doing so, military organizations can continue to implement best practices in policy development in support of the brave individuals who serve their country and the people they vow to protect.

\section{References}

Allen, T. D., Eby, L. T., Poteet, M. L., Lentz, E., \& Lima, L. (2004). Career benefits associated with mentoring for protégés: A meta-analysis. Journal of Applied Psychology, 89, 127-136.

America Abroad (2017, July 10). How the US military uses behavioral economics to fight ISIS. The World. https://www.pri.org/stories/2017-07-10/how-us-military-uses-behavioral-economicsfight-isis.

Ariely, D. (2008). Predictably irrational. London: Harper Collins Publishers.

Behavioural Insights Team (BIT) (2015). Update report 2013-2015. Retrieved 15 December, 2021 from https://38r8om2xjhhl25mw24492dir.wpengine.netdna-cdn.com/wp-content/uploads/ 2015/08/BIT_Update\%20Report-Final-2013-2015.pdf

Boksmati, N., Butler-Henderson, K., Anderson, K., \& Sahama, T. (2016). The effectiveness of SMS reminders on appointment attendance: A meta-analysis. Journal of Medical Systems, 40(4), 90.

Brendryen, H., Johansen, A., Duckert, F., \& Nesvåg, S. (2017). A pilot randomized controlled trial of an internet-based alcohol intervention in a workplace setting. International Journal of Behavioral Medicine, 24(5), 768-777.

Businessballs. (2014). Nudge theory. https://www.businessballs.com/improving-workplace-perfor mance/nudge-theory/

Central Innovation Hub, Privy Council Office (Canada). (2016, March). First annual report. https:// www.canada.ca/content/dam/pco-bcp/documents/pdfs/inn-inn/rpt1_2016-eng.pdf

Chang, H., \& Beilock, S. L. (2016). The math anxiety-math performance link and its relation to individual and environmental factors: A review of current behavioral and psychophysiological research. Current Opinion in Behavioral Sciences, 10, 33-38.

Cialdini, R. B. (2001). Influence: Science and practice (4th ed.). Boston: Allyn \& Bacon.

Cialdini, R. B., \& Goldstein, N. J. (2004). Social influence: Compliance and conformity. Annual Review of Psychology, 55, 591-621.

Cialdini, R. B., Reno, R. R., \& Kallgren, C. A. (1990). A focus theory of normative conduct: Recycling the concept of norms to reduce littering in public places. Journal of Personality and Social Psychology, 58(6), 1015-1026.

Dolan, P., Hallsworth, M., Halpern, D., King, D., Metcalfe, R., \& Vlaev, I. (2012). Influencing behaviour: The mindspace way. Journal of Economic Psychology, 33, 264-277. 
Durantini, M., Albarracin, D., Mitchell, A., Earl, A., \& Gillette, J. (2006). Conceptualizing the influence of social agents of behavior change: A meta-analysis of the effectiveness of HIV-prevention interventionists for different groups. Psychological Bulletin, 132, 212-248.

Gilovich, T. D., Husted Medvec, V., \& Savitsky, K. (2000). The spotlight effect in social judgment: An egocentric bias in estimates of the salience of one's own action and appearance. Journal of Personality and Social Psychology, 78(2), 211-222.

Gooch, S., \& Kemp, C. (2018). Results of a messaging study to encourage CAF prospects to continue with the application process (Nudge 03: File Closed - No Further Contact [NFC] [Generic]). Director General Military Personnel Research and Analysis Scientific Letter DRDCRDDC-2018-L234. Ottawa: Defense Research and Development Canada.

Halpern, D. (2016). Inside the nudge unit: How small changes can make a big difference. London: Ebury Press.

Hasvold, P. E., \& Wootton, R. (2011). Use of telephone and SMS reminders to improve attendance at hospital appointments: A systematic review. Journal of Telemedicine and Telecare, 17(7), 358-364.

Kahneman, D. (2011). Thinking, fast and slow. New York: Farrar, Straus and Giroux.

Kahneman, D., \& Tversky, A. (1972). Subjective probability: A judgment of representativeness. Cognitive Psychology, 3, 430-454.

Kahneman, D., \& Tversky, A. (1973). On the psychology of prediction. Psychological Review, 80, 237-251.

Kahneman, D., \& Tversky, A. (1979). Prospect theory: An analysis of decisions under risk. Econometrica, 47, 263-291.

Kersbergen, I., Oldham, M., Jones, A., Field, M., Angus, C., \& Robinson, E. (2018). Reducing the standard serving size of alcoholic beverages prompts reductions in alcohol consumption. Addiction, 113(9), 1598-1608.

Khan, H., \& Hardy, E. (2018). Behavioural Insights Project: Engaging Canadian women with a career in the armed forces. https://www.canada.ca/en/innovation-hub/services/reportsresources/engaging-women-career-armed-forces.html

Kosters, M., \& Van der Heijden, J. (2015). From mechanism to virtue: Evaluating nudge theory. Evaluation, 21(3), 276-291.

Linos, E., Reinhard, J., \& Ruda, S. (2017). Levelling the playing field in police recruitment: Evidence from a field experiment on test performance. Public Administration, 95, 943-956.

Lockwood, P. (2006). "Someone like me can be successful": Do college students need same-gender role models? Psychology of Women Quarterly, 30, 36-46.

Manigart, P., op den Buijs, T., van Doorn, E., Jonsson, E., Lecoq, V., Moelker, R., Österberg, J., Otis, N., Brundtland Steder, F., \& Szvircsev Tresch, T. (2018). The impact of demographic change on recruitment and retention of personnel in European armed forces. European Defence Agency Final Report.

Mullainathan, S., \& Thaler, R. H. (2015). Behavioral economics. In J. D. Wright (Ed.), International encyclopedia of the social and behavioral sciences (2nd ed.). Amsterdam: Elsevier.

O'Keefe, D. F., Gooch, S., \& Kemp, C. (2018a). Results of a CAF messaging study to encourage applicants to consider priority occupations (Nudge 01: File Closed - No SIP). DRDC-RDDC2018-L374.

O'Keefe, D. F., Gooch, S., \& Kemp, C. (2018b). Results of a CAF messaging study to encourage CAF prospects to continue with the application process (Nudge 02: File Closed - NFC). Director General Military Personnel Research and Analysis Letter Report DRDC-RDDC2018-L373. Ottawa: Defense Research and Development Canada.

Park, L. E., \& Crocker, J. (2013). Pursuing self-esteem: Implications for self-regulation and relationships. In V. Zeigler-Hill (Ed.), Current issues in social psychology: Self-esteem (pp. 43-59). New York: Psychology Press.

Reisch, L. A., \& Sunstein, C. R. (2016). Do Europeans like nudges? Judgement and Decision Making, 11(4), 310-325. 
Results of the Canada Revenue Agency's 2015-2018 Underground Economy Strategy, (2018). Retrieved December 16, 2021, from https://www.canada.ca/en/revenue-agency/programs/ about-canada-revenue-agencycra/corporate-reports-information/results-underground-economystrategy-2015-2018.html\#toc11

Rutter, T. (2015). The rise of nudge - The unit helping politicians to fathom human behaviour. Guardian Public Leader's Network (online). https://www.theguardian.com/public-leadersnetwork/2015/jul/23/rise-nudge-unit-politicians-human-behaviour.

Samuelson, W., \& Zeckhauser, R. (1988). Status quo bias in decision making. Journal of Risk and Uncertainty, 1, 7-59.

SBST. (2015). Social and behavioral Science Team annual report. https://sbst.gov/download/2015exec-summary.pdf

Scharfstein, D. S., \& Stein, J. C. (1990). Herd behavior and investment. American Economic Review, 80, 465-479.

Science and Technology Select Committee. (2011). Behaviour change. House of Lords. www. parliament.uk/hlscience

Stanovich, K. E., \& West, R. F. (1998). Individual differences in rational thought. Journal of Experimental Psychology: General, 127(2), 161-188. https://doi.org/10.1037/0096-3445.127. 2.161 .

Stanovich, K. E., \& West, R. F. (2000). Individual differences in reasoning: Implications for the rationality debate? Behavioral and Brain Sciences, 23, 645-726.

Stanovich, K. E., West, R. F., \& Toplak, M. E. (2011). The complexity of development predictions from dual process models. Developmental Review, 31, 103-118.

Sylvester, B. D., \& Gooch, S. (2021). A Realist Review of Nudge Interventions to Decrease Alcohol and Tobacco Consumption, DRDC-RDDC-2021-R136

Sylvester, B. D., Gooch, S., \& Laplante, J. (2021). Increasing Survey Completion Rates: Experimental Evidence from Project Horizon Phase 5, DRDC-RDDC-2021-R198

Sylvester, B. D., Howell, G. \& Messervey, D. (2021). Increasing Survey Response Rates: Experimental Evidence from the 2018 Defence Workplace Well-being Survey. DRDC-RDDC-2021L196

Thaler, R. H., \& Sunstein, C. R. (2008). Nudge: Improving decisions about health, wealth, and happiness. New Haven: Yale University Press.

Tversky, A., \& Kahneman, D. (1973). Availability: A heuristic for judging frequency and probability. Cognitive Psychology, 5, 207-232.

Tversky, A., \& Kahneman, D. (1974). Judgment under uncertainty: Heuristics and biases. Science, $185,1124-1131$. 
Tversky, A., \& Kahneman, D. (1981). The framing of decisions and the psychology of choice. Science, 211, 453-458.

Weinstein, N. D., \& Klein, W. M. (1996). Unrealistic optimism: Present and future. Journal of Social and Clinical Psychology, 15(1), 1-8.

Winkler, G., Streber, A., \& Filipiak-Pittroff, B. (2016). Small changes in choice architecture in a military lunchroom: Do they nudge towards healthier food choices. Ernahrungs Umschau, 63(3), 59-61.

Xiao, Y., \& Watson, M. (2019). Guidance on conducting a systematic literature review. Journal of Planning Education and Research, 39(1), 93-112.

Open Access This chapter is licensed under the terms of the Creative Commons Attribution 4.0 International License (http://creativecommons.org/licenses/by/4.0/), which permits use, sharing, adaptation, distribution and reproduction in any medium or format, as long as you give appropriate credit to the original author(s) and the source, provide a link to the Creative Commons license and indicate if changes were made.

The images or other third party material in this chapter are included in the chapter's Creative Commons license, unless indicated otherwise in a credit line to the material. If material is not included in the chapter's Creative Commons license and your intended use is not permitted by statutory regulation or exceeds the permitted use, you will need to obtain permission directly from the copyright holder.

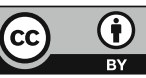

